\title{
Índice para cidades saudáveis como suporte as políticas públicas: análise de indicadores de Desenvolvimento Social e sua aplicação em Uberlândia, Minas Gerais
}

Index for healthy cities as a support for public policies:

analysis of Social Development indicators and their application in Uberlândia, Minas Gerais

Índice para ciudades saludables cómo soporte las políticas públicas:

análisis de indicadores de Desarrollo Social y su aplicación en Uberlândia, Minas Gerais

Josimar dos Reis de Souza

Doutorando em Geografia, Instituto de Geografia, UFU, Brasil. josimarsouza@ufu.br

Beatriz Ribeiro Soares

Doutora, Professora Titular do Instituto de Geografia, UFU, Brasil. brsoares@ufu.br 

No Brasil, a partir de 1950 o processo de urbanização se intensificou levando a população para as cidades em busca de trabalho e melhores condições de vida. Isso se deu, sobretudo, pelo estímulo ao processo de industrialização (GOMES; SOARES, 2004). As alterações ocorridas nas décadas seguintes levaram ao retrato atual de grandes diferenças socioeconômicas e de qualidade de vida em um mesmo ambiente urbano, com significativa parcela da população brasileira vivendo em condições precárias, sem acesso a serviços básicos de qualidade, tais como saneamento básico, saúde e educação.

Na busca por melhorias da qualidade de vida da população tem se intensificado nas últimas décadas os estudos sobre as cidades na perspectiva de se buscar a realização de transformações positivas no espaço urbano. Estes estudos visam discutir os problemas inerentes aos centros urbanos de forma a buscar alternativas para a melhoria da qualidade de vida nas cidades. Um dos movimentos que tem ampliado e difundidos suas discussões e pesquisas é o movimento pela construção de Cidades Saudáveis.

Cidades Saudáveis é o nome que se dá a um projeto de desenvolvimento social, que tem a saúde e suas múltiplas determinações como centro das atenções. É também um movimento de luta por um estilo de desenvolvimento sustentável, que satisfaça as necessidades das gerações atuais sem comprometer a capacidade das futuras de satisfazer suas próprias necessidades (GUIMARÃES, 2000, p. 15).

Para o desenvolvimento físico e social da cidade e proposição de Políticas Publicas eficazes (foco da busca pela construção de Cidades Saudáveis), se faz necessário conhecer a cidade e suas diferentes dimensões, que incluem a educação, a saúde, o meio ambiente e desenvolvimento social. Somente a partir da exposição do panorama/realidade da cidade se torna possível definir estratégias de intervenção para a construção de cidades mais saudáveis, seja através da melhoria da qualidade de vida, como também, da diminuição gradativa da exclusão social urbana.

Los indicadores simples y sintéticos juegan un papel importante en la política pública, porque ayudan a construir percepción pública de problemas complejos. Además, proveen información cuantitativa para evaluar la efectividad de las alternativas de decisión pública. Estos son importantes instrumentos para el Planeamiento de las ciudades (ESCOBAR, 2003, p. 7).

Acerca da necessidade de se buscar Políticas Públicas mais saudáveis e eficazes, de acordo com Souza e Soares (2014), para buscar alcançar a cidade saudável, as ações de governança, assumem, portanto, o comprometimento de legislar suas políticas públicas buscando a melhoria de qualidade de vida de população. Entretanto, muitas vezes pela burocratização e pelas dificuldades de intersetoriedade das políticas públicas, as ações são iniciadas e não concluídas. Desta maneira se faz necessário o compromisso formal para a adoção de estratégias mais eficazes para a diminuição das desigualdades. 
A partir das considerações aqui elencadas e das premissas que constituem o Movimento Cidades Saudáveis, (i) que a Cidade Saudável é constituída através do desenvolvimento dos ambientes físico e social, (ii) que este desenvolvimento é alcançado através de Políticas Públicas urbanas voltadas para a melhoria da qualidade de vida, (iii) que essas Políticas Públicas são pautadas nas intervenções ligadas ao Planejamento Urbano, (iv) e que o estudo de indicadores é um importante instrumento de orientação e avaliação das Políticas Públicas; que o presente estudo visou contribuir com a metodológica de Índice para Cidades Saudáveis (ICS) a partir de indicadores urbanos de desenvolvimento social e sua aplicação na área urbana de Uberlândia, Minas Gerais, com o intuito de avaliar o quão saudável a cidade se encontra em determinado momento, visando auxiliar na implementação de políticas públicas saudáveis.

0 presente estudo se justifica pela necessidade de desenvolver novos instrumentos que auxiliem na busca pela melhoria da qualidade de vida da população e no gerenciamento do dinheiro público através da execução de Políticas Públicas mais eficazes, que possibilitem o desenvolvimento das cidades e superação dos desafios urbanos. Busca-se com a proposta de índice, contribuir com avanços, através de novas estratégias de análise, para o desenvolvimento de ambientes urbanos mais saudáveis, foco da busca pela construção de Cidades Saudáveis.

\section{PROCEDIMENTOS METODOLÓGICOS}

A metodologia de análise de indicadores de desenvolvimento social foi realizada a partir de proposição metodológica de Souza (2016) e se baseou nas etapas que serão apresentadas a seguir.

\subsection{Escolha dos indicadores de análise}

Para a dimensão Desenvolvimento Social foram definidas duas variáveis (renda e qualidade da habitação), conforme figura 1. Entende-se que para que haja de fato desenvolvimento social com foco na melhoria das condições de vida há necessariamente que se avaliar a renda, as condições de habitação e questões relativas ao emprego. 



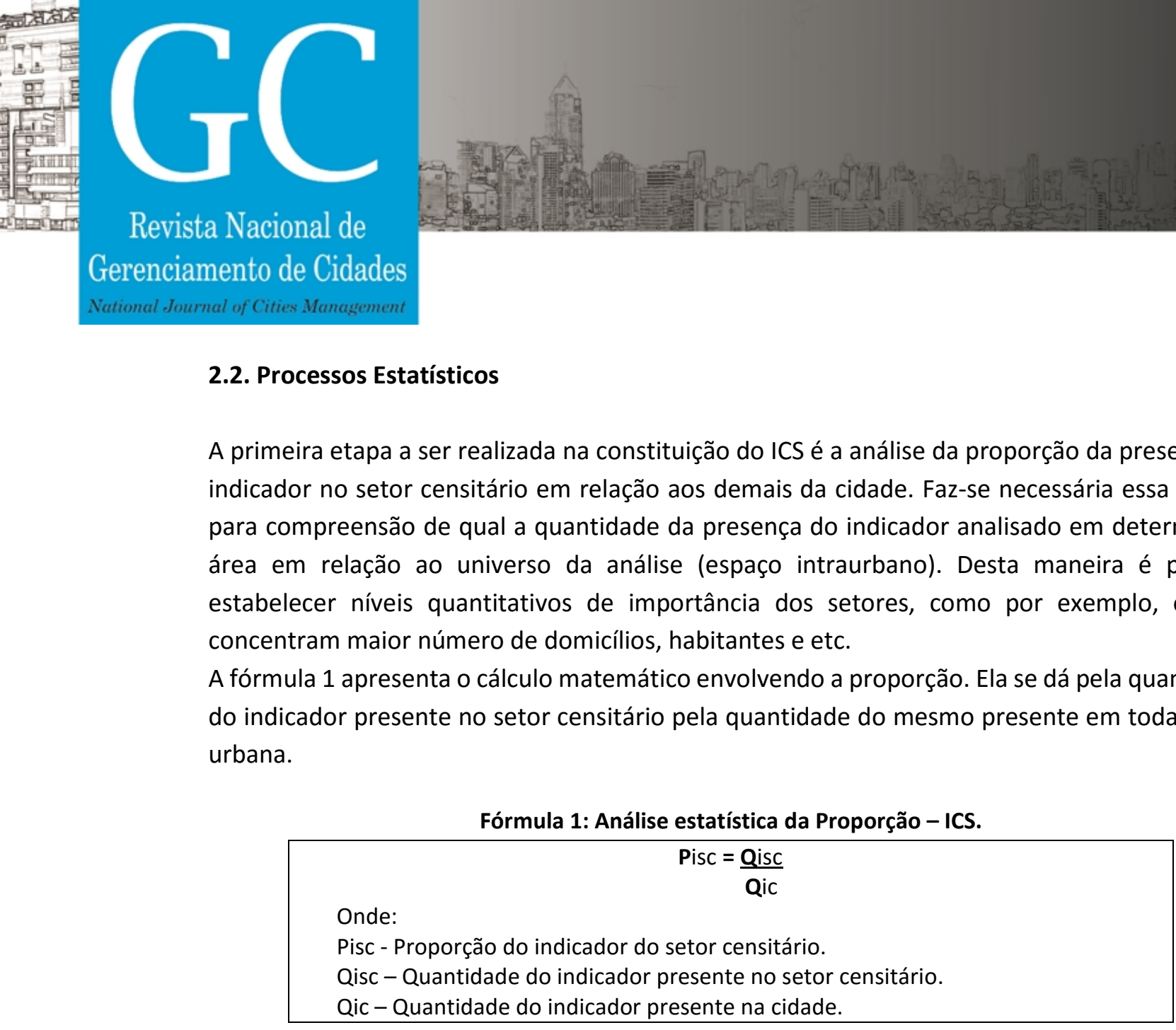

Revista Nacional de

\subsection{Processos Estatísticos}

A primeira etapa a ser realizada na constituição do ICS é a análise da proporção da presença do indicador no setor censitário em relação aos demais da cidade. Faz-se necessária essa análise para compreensão de qual a quantidade da presença do indicador analisado em determinada área em relação ao universo da análise (espaço intraurbano). Desta maneira é possível extelecer niveis quantitativos de importância dos setores, como por ex

A fórmula 1 apresenta o cálculo matemático envolvendo a proporção. Ela se dá pela quantidade em toda a área urbana.

Org.: SOUZA, 2016.

A segunda etapa analítica do ICS diz respeito a relação que o indicador do setor censitário tem com o universo dele mesmo. Trata-se da necessidade de buscar uma compreensão mais completa dos indicadores. A aplicação estatística da relação é apresentada na fórmula 2 . Ela se dá pela quantidade do indicador presente no setor censitário em relação ao número de habitantes ou de domicílios existentes no setor.

Fórmula 2: Análise estatística da Relação - ICS.

Rics $=\frac{\text { Qisc }}{\mathbf{Q x}}$
Onde:
Rics - Relação do indicador do setor censitário.
Qisc - Quantidade do indicador presente no setor censitário.
Qx - Quantidade de habitantes ou quantidade de domicílios no setor.

Org.: SOUZA, 2016.

A obtenção da distribuição dos indicadores pela área urbana, terceira etapa, é realizado a partir da utilização da função média aritmética ponderada presente no software ArcGiS 10.1. Esse procedimento estatístico leva em consideração as variáveis envolvendo a relação e a proporção de cada indicador. Trata-se de cálculo matemático envolvendo a média, mediana e desvio padrão (MANUAL ARCGIS, 2010).

A quarta etapa contempla a normatização dos resultados obtidos da proporção, relação e distribuição. Esta é essencial e muito utilizada em análises estatísticas de dados, pois possibilita 



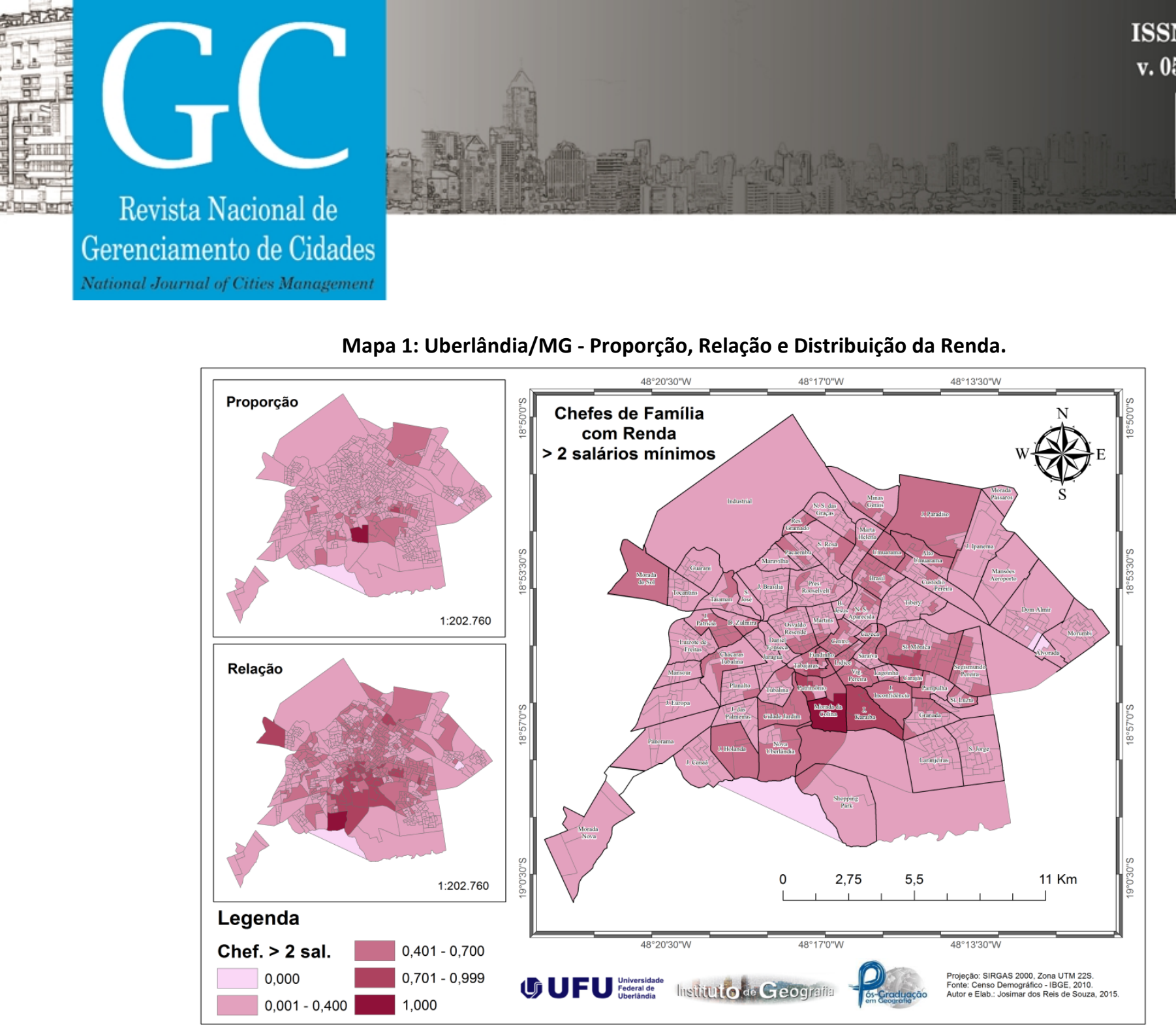

Mapa 1: Uberlândia/MG - Proporção, Relação e Distribuição da Renda.

Fonte. BGE, 2010. Autor e Elab.: SOUZA, 2015.

O resultado da proporção demonstrou que a maior parte dos setores censitários correspondeu a normatização entre 0,001-400. Isso significa que na maioria deles se concentram entre 15 e 264 chefes de família com renda maior que dois salários mínimos. O setor censitário que apresentou maior número de chefes de família com renda maior que dois salários mínimos foi o localizado no bairro Morada da Colina, com 669 chefes de família com renda maior que dois salários mínimos, seguido por setores concentrados na zona sul e zona leste de Uberlândia.

A relação de renda se deu pelo número de chefes de família que recebem mais de dois salários mínimos pelo número total de chefes de cada setor censitários. Essa relação equivale a densidade de renda. A análise visou identificar as áreas da cidade com maior renda em relação a população dessas áreas.

A relação da renda em Uberlândia no ano de 2010 apresentou a maior parte dos setores com normatização entre 0,001-400, que corresponde a densidade de renda entre 0,019 e 0,400. 0 setor que compõem o bairro Morada da Colina também apresentou a maior densidade de renda, valor igual a 1,000, o que significa que nesse bairro todos os chefes de família possuem renda maior que dois salários mínimos.

A distribuição de renda em Uberlândia, realizada através da média aritmética entre a proporção e a relação, apresentou setores em sua maioria com baixos níveis de renda (normatização entre 
$0,001-0,400)$, isso significa que esses setores possuem as menores rendas em relação aos demais setores da cidade.

Os setores com maior renda se encontram localizados na zona sul, com destaque para os localizados nos bairros Morada da Colina e Jardim Karaíba. Na zona leste há destaque para o loteamento Jardim Finotti, no bairro Santa Mônica, que apresentou bons níveis.

A partir do resultado da proporção, relação e distribuição, os bairros foram classificados em: nível alto de distribuição de renda, nível médio de distribuição de Renda e nível baixo de distribuição de renda. Dos 69 bairros existentes em Uberlândia apenas três se destacam como sendo de nível alto de distribuição de renda, são eles: Morada da Colina, Jardim Karaíba, e Patrimônio (ambos com condomínios fechados), com destaque para o primeiro, que apresentou todos os chefes de família com renda superior a dois salários mínimos, inclusive com renda maior que 20 salários mínimos.

\subsection{Variável Qualidade da Habitação (Indicador Domicílios Particulares Permanentes)}

A análise do indicador domicílios particulares permanentes é importante, pois esses domicílios são caracterizados pelo padrão de construção para fins de moradia, ou seja, são construções destinadas a abrigar moradores. Isso os diferencia dos domicílios improvisados, que são construções impróprias à moradia. Esses domicílios são caracterizados por construções não voltadas a habitação ou por de barracos de lona, entre outros.

O mapa 2 apresenta a proporção, relação e distribuição dos domicílios particulares permanentes em Uberlândia, com base nos dados do censo demográfico de 2010.

A proporção foi analisada a partir da quantidade de domicílios particulares permanentes de cada setor em relação a todos os presentes da cidade. $O$ resultado da proporção aponta que a maioria dos setores de Uberlândia correspondeu a normatização 0,001 - 400, que significa que esses possuem entre 2 e 235 domicílios particulares permanentes.

O setor censitário que apresentou o maior número de domicílios particulares permanentes se encontra localizado no bairro São Jorge. Trata-se do com maior número de domicílios e de habitantes, conforme verificado na análise da distribuição domiciliar e de habitantes.

A relação foi verificada a partir do número de domicílios particulares permanentes pelo total de domicílios presentes no setor. Essa relação equivale a densidade de domicílios particulares permanentes.

No ano de 2010 a maior parte dos setores de Uberlândia apresentou densidade igual a 1,000, que corresponde a setores compostos completamente por domicílios particulares permanentes. Também parte significativa dos setores censitários apresentou densidade alta, acima de 0,700, o que demonstra que de maneira geral, Uberlândia é formada por domicílios construídos para fins de habitação. 


necessitam de atenção da gestão pública. Trata-se de metodologia que visa contribuir com a melhoria da gestão urbana e principalmente com a melhoria da qualidade de vida da população. Entretanto, no jogo de interesses social, público e particular, impera-se a dinâmica do capital, marcada pelas desigualdades socioespaciais, sendo que nas áreas urbanas esses processos se apresentam de forma mais abrangente. Igualmente, a população com acesso reduzido a essa dinâmica, se acomoda em regiões da cidade com maior escassez de equipamentos urbanos. $A$ essa parcela da população cabe maior atenção da gestão pública, visto que, se parte da cidade não possui bons níveis de qualidade de vida, a mesma como um todo não é saudável.

Em contra partida, tem-se intensificado nos últimos anos ações de busca pela melhoria do ambiente urbano, no qual aqui se destacou o movimento por Cidades Saudáveis. Esse projeto de cidade tem se consolidado sendo importante no contexto contemporâneo, visto que partes das cidades se encontram doentes, insalubres, com população vivendo em condições de miséria e pobreza. Portanto, se torna urgente a busca pela superação desse quadro.

\section{REFERÊNCIAS}

ARCGIS. Manual básico de orientações. São Paulo: ArcGIS, 2010. 200 p.

ESCOBAR, L. Indicadores sintéticos de calidad ambiental: un modelo general para grandes zonas urbanas. Revista eure, n. 32, v. 96, 20003. p. 73-98.

GOMES, M. A. S.; SOARES, B. R. Reflexões sobre qualidade ambiental urbana. Estudos Geográficos: Revista Eletrônica de Geografia, Rio Claro, v. 2, n. 2, 2004. p. 21-30.

GUIMARÃES, R. P. Agenda 21 e desenvolvimento sustentável: o desafio político da sustentabilidade. Debates SócioAmbientais, v. 4, n. 11, 2000. p.10-13.

INSTITUTO BRASILEIRO DE GEOGRAFIA E ESTATÍSTICA (IBGE). Base de informações do Censo Demográfico 2010: Resultados do Universo por setor censitário. Rio de Janeiro: IBGE, 2011. 125 p.

MENDES, R. Cidades Saudáveis no Brasil e os Processos Participativos: Os Casos de Jundiaí e Maceió. 2000. $232 \mathrm{f}$. Tese (Doutorado em Saúde Pública) - Faculdade de Saúde Pública - Universidade de São Paulo, São Paulo, 2000.

MORATO, R. G. Análise da Qualidade de Vida Urbana no Município de Embu/SP. 2004. 108 f. Dissertação (Mestrado em Geografia Física) - USP/FFLCH, São Paulo, 2004.

ORGANIZAÇÃO DAS NAÇÕES UNIDAS (ONU). World Urbanization Prospects The 2009 Revision. Nova lorque: ONU, 2010. 47 p. Disponível em: http://esa.un.org/unpd/wup/Documents/WUP2009_Highlights_Final.pdf. Acesso em: março de 2015.

ORGANIZAÇÃO PARA A COOPERAÇÃO E DESENVOLVIMENTO ECONÔMICO (OCDE). Urban environmental indicators. Paris: OCDE, 1978. 65 p.

PROGRAMA DAS NAÇÕES UNIDAS PARA O DESENVOLVIMENTO (PNUD). Índice de Desenvolvimento Humano - IDH. Nova lorque: ONU, 2010.

SOUZA, J. R. Trilhando por Cidades Saudáveis: contribuição metodológica de índice e aplicação em Uberlândia, MG. 265 f. Dissertação (Mestrado em Geografia) - Instituto de Geografia - Universidade Federal de Uberlândia, Uberlândia, 2016. 
